\title{
Life History and Description of Immature Stages of Aciurina thoracica (Diptera: Tephritidae) on Baccharis sarothroides in Southern California
}

\author{
DAVID H. HEADRICK AND RICHARD D. GOEDEN
}

Department of Entomology, University of California, Riverside, CA 92521

\begin{abstract}
Ann. Entomol. Soc. Am. 86(1): 68-79 (1993)
ABSTRACT Aciurina thoracica Curran forms galls on branches of at least three species of Baccharis in southern California. The egg, second and third instars, and puparium obtained from B. sarothroides Gray are described and illustrated. Aciurina thoracica's median oral lobe is described and illustrated. The egg is inserted singly into branch tips of $B$. sarothroides in early spring. Gall and larval growth continue through summer and fall, and pupariation occurs in early winter. Adults emerge in late winter or early spring, mate, and oviposit into newly forming branch tips. Adult behavior including courtship and copulation is described and compared with other Aciurina species. Principal hymenopterous natural enemies of $A$. thoracica include two solitary, primary endoparasitoids, Dinarmus sp. (Pteromalidae) and Eurytoma sp. (Eurytomidae); two solitary primary ectoparasitoids, Pteromalus sp. and Mesopolobus sp. (Pteromalidae); and Eupelmus spp. (Eupelmidae) reared as solitary, primary endo- and ectoparasitoids.
\end{abstract}

KEY WORDS biology, galls, mating behavior

THIS STUDY is derived from field studies begun in 1989 on the tephritid associates of Baccharis sarothroides Gray in southern California, and it continues a series of life-history studies on nonfrugivorous tephritids associated with Asteraceae in southern California. Much of what was known about the genus Aciurina was strictly taxonomic before Tauber \& Tauber (1967) conducted their study of the biology of Aciurina ferruginea (Doane). Wangberg (1981) described the biologies and galls of eight species of Aciurina on Chrysothamnus spp. in Idaho. The most extensive studies to date on the biologies of Aciurina were conducted in New Mexico on A. trixa Curran (Dodson \& George 1986, Dodson 1987). Both studies treated host plant associations, reproductive behavior, and morphology; the former study also discussed taxonomy. Jenkins (1990) described the reproductive behavior of A. mexicana (Aczél) in Arizona.

This article reports field and laboratory data on the immature stages, hosts, biology, mating behavior, and natural enemies of $A$. thoracica Curran.

\section{Materials and Methods}

Our field studies of the biology of A. thoracica began in 1989 during the second year of a severe drought in southern California. Consequently, flies became progressively less common and more difficult to study in the field during each of 2 successive yr.

We collected galls and adults on $B$. sarothroides at Otay Mesa, Chariot Canyon, and $5 \mathrm{~km}$ south of Alpine, all in southern San Diego County. The Otay Mesa site overlooks San Ysidro just north of Tijuana, Mexico, at $45 \mathrm{~m}$ elevation. The Alpine site is inland northeastward at $480 \mathrm{~m}$ elevation. Collections in Chariot Canyon south of Banner were made at $1,050 \mathrm{~m}$ elevation.

Field data were supplemented by laboratory cagings of swept or reared single males and females or paired reared adults of opposite sex. The adults were reared from larvae and puparia dissected from galls held separately in cottonstoppered, glass shell vials within humidity chambers at $22-24^{\circ} \mathrm{C}$ and $76 \% \mathrm{RH}$. Adults were subsequently held in $850-\mathrm{ml}$, clear plastic cages fitted with screened lids for ventilation and basal water reservoirs. Absorbent cotton wicks and bouquets of excised vegetative branches of $B$. sarothroides passed through a hole in each cage bottom. Honey striped with a bulb and syringe on the underside of the lids provided food for the flies.

Mating trials employed disposable plastic $10-\mathrm{cm}$ petri dish arenas in the manner of Jenkins (1990), modified by the inclusion of a flattened, water-moistened pad of absorbent cotton spotted with honey. The 1 -h trials were run at room tem- 
perature under artificial lighting between 1100 and 1500 hours PST, when males readily displayed courtship behavior; however, during the 1.5-d trials, copulation was observed only after 1400 hours, and usually at dusk under natural lighting.

Immature stages were described using scanning electron microscopy (SEM) from five eggs dissected from gravid females as well as five each of second and third instars and two puparia dissected from branch tip galls on B. sarothroides. All stages were fixed in $70 \% \mathrm{EtOH}$, later rehydrated to distilled water, and osmicated for $24 \mathrm{~h}$. Specimens were then dehydrated to $100 \%$ $\mathrm{EtOH}$ in a graded series of acidulated EtOH, critically point dried, mounted on stubs, and sputter coated for SEM (Headrick \& Goeden 1990 , 1991). Micrographs were prepared at $15 \mathrm{kV}$ accelerating voltage with Polaroid $55 \mathrm{P} / \mathrm{N}$ film on a JEOL JSM-C35 SEM, located in the Department of Nematology, University of California, Riverside. Eggs, second and third instars, and puparia are described using the format and nomenclature adopted by Headrick \& Goeden (1990), as modified by Headrick \& Goeden (1991). Description of the second instar is limited to observed differences from the third instar.

The mouthparts of three third instars of $A$. thoracica were dissected in $70 \% \mathrm{EtOH}$ to which $1 \%$ alcoholic acid fuchsin was added as a visual aid. Larvae were obtained from the immature Tephritidae research collection of D.H.H. Nomenclature for the cephalopharyngeal skeleton follows that of Teskey (1981). Plant names follow Boldt (1989); Aciurina names follow Steyskal (1984) or Dodson \& George (1986).

Voucher specimens of $A$. thoracica from each study site are located in the research collection of R.D.G. (Department of Entomology, University of California, Riverside); voucher specimens of parasitoids are in a separate collection of reared hymenopterous parasitoids of California Tephritidae belonging to R.D.G. Means \pm SEM are provided throughout the paper.

\section{Results and Discussion}

Taxonomy. Aciurina thoracica was described from a single female collected from San Diego County, CA (Curran 1932). It belongs to the Aplopappi group as defined by Steyskal (1984), which also contains A. aplopappi (Coquillett) and A. mexicana. This group is characterized by a similar habitus and wing venation as well as several distinguishing features of the ovipositor (Steyskal 1984).

Egg. Ova white, fusiform; 25 averaged $0.87 \pm$ $0.01 \mathrm{~mm}$ long (range, $0.78-0.92 \mathrm{~mm}$ ), $0.31 \pm 0.01$ mm wide (range, $0.26-0.37 \mathrm{~mm}$ ) (Fig. $1 \mathrm{~A}$ ); anterior half bears distinct polygonal reticulations on chorion increasing in height near anterior pole; anterior end tapers to honey-combed pedicel,
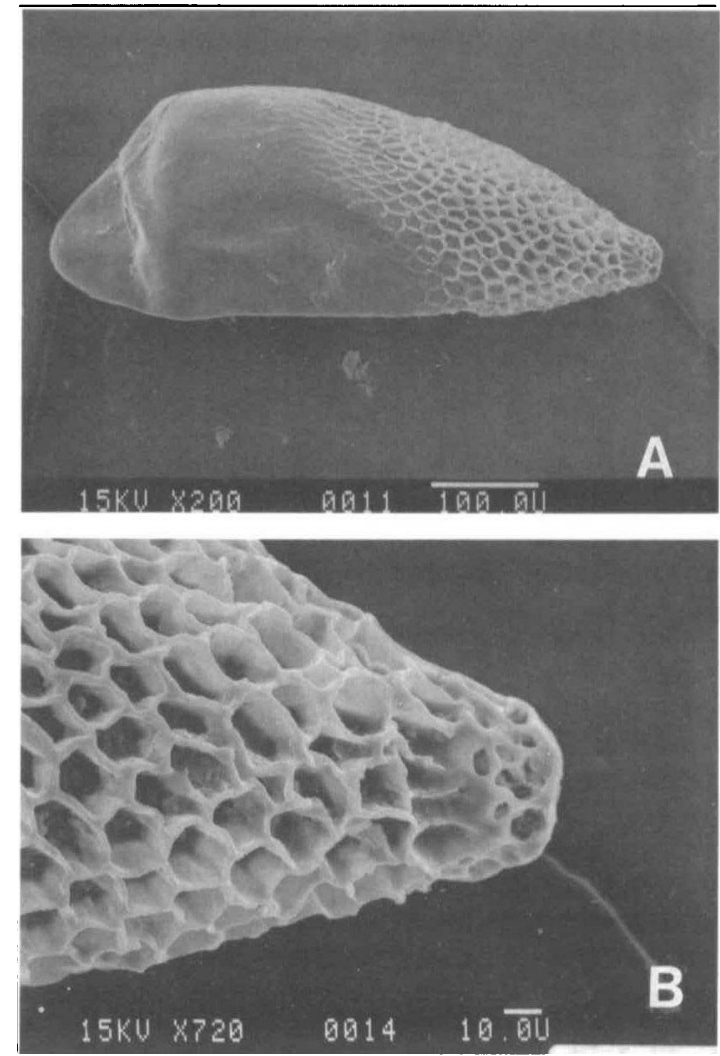

Fig. 1. Egg of A. thoracica: (A) habitus, dissected from gravid female; (B) detail of pedicel.

$0.05 \pm 0.002 \mathrm{~mm}$ long, $0.08 \pm 0.002 \mathrm{~mm}$ wide (Fig. 1B); polygonal reticulations arise around middle of egg body, farther down one side than opposite side; posterior end smooth, rounded, fragile.

The posterior end is embedded in host plant tissue at oviposition at an angle, such that the exposed side of the egg opposite the branch bears reticulations farther along the egg body than the side nearest the branch (Fig. IA). The eggs of $A$. thoracica are similar in size and shape to those of Tephritis baccharis (Coquillett) (Goeden \& Headrick 1991a) and other Tephritis spp. (Jenkins \& Turner 1989). Noteworthy differences in the egg chorion of $A$. thoracica from that of $T$. baccharis are no distinct pores circumscribing the pedicel, deeper reticulations, papillate structures at the polygonal junctions, and a verrucate surface. The ova of $A$. thoracica also differ markedly from eggs of A. ferruginea illustrated by Tauber \& Tauber (1967), which have elongate pedicels. Our dissections of swept, gravid females of $A$. ferruginea confirmed this finding. The ova of $A$. ferruginea are similar in size and shape to those of Paracantha gentilis Hering, but are not stored in the ovaries as illustrated for the latter species (Headrick \& Goeden 1990; unpublished data). It is unclear why $A$. ferruginea has 
an egg with a long pedicel and $A$. thoracica does not. Paracantha cultaris (Coquillett), like P. gentilis, has eggs with elongate pedicels (Cavender \& Goeden 1984).

Third Instar. Third instar creamy white, oblong-elliptical, dorsally rounded, ventrally flattened; superficially smooth; lacks distinct segmental depressions; (Fig. 2A); mouth hooks tridentate; teeth stout, sharply curved ventrad (Fig. 2B, 1; Fig. 3); median oral lobe laterally compressed, tapers anteriad between mouth hooks; paired, thin, darkly pigmented flanges project ventrad from darkly pigmented dorsal ribs supporting ventral lobe (Fig. 2B, 2; Fig. $3 \mathrm{~A}$ and $B)$; ventral lobe of median oral lobe smooth, attached basally to labial lobe (Fig. 3A); labial lobe divides anterioventral margin of gnathocephalon, muscles insert on ventral margin; labial lobe bears two pore sensilla anteriorly (Fig. 2B, 3; best seen in Fig. 4D, 2); labial sclerite quadrangular, medially divided, darkly pigmented, articulates laterally with ventral margins of paired hypostomal sclerites, paired apodemes project dorsoanteriad (Fig. $3 \mathrm{~A}$ and $\mathrm{B}$ ); hypostomal sclerites rounded to form cylindrical passage for esophagus, joined by dorsal bridge posteriorly; labial sclerite apodemes articulate with dorsal ribs; both ventral lobe and labial lobe attached to ventral surface of labial sclerite (Fig. $3 A)$; muscles originate on labial sclerite of cephalopharyngeal skeleton, insert on ventrally projecting flanges of dorsal ribs (Fig. 3A); gnathocephalon smooth, conical, bearing few rugose pads laterad of sensory lobes (Fig. 2B, 4); anterior sensory lobes located near mouth opening (Fig. 2B, 5); each bearing four distinct sensilla: terminal sensory organ (Fig. $2 \mathrm{C}, 1$ ), pit sensory organ (Fig. 2C, 2), lateral sensory organ (Fig. 2C, 3), unnamed sensillum (Fig. 2C, 4); dorsal sensory organ, a single papilla, lies mediad of anterior sensory lobes (Fig. 2C, 5); stomal sense organs lie ventrolaterad of anterior sensory lobes (Fig. 2C, 6); each bearing several pore- and coneshaped sensilla; two distinct lobes lie laterally and ventrolaterally on gnathocephalon, each bearing smaller, dome-shaped, smooth, verrucate papilla with central pore (Fig. 2B, $6 \mathrm{a}$ and b, respectively); prothorax smooth, circumscribed by two rows of flattened, dome-shaped sensilla; anterior spiracles dorsolateral on posterior margin, each bearing four papillae (Fig. 2D, arrow); mesothorax, metathorax, and abdominal segments similar in appearance, bearing irregular patches of minute, rounded, posteriorly oriented acanthae (Fig. 2E, arrow); mesothorax bears lateral spiracular complex with two, smooth, domeshaped sensilla, (Fig. 2F, 1), anteriad of spiracle (Fig. 2F, 2); metathoracic and abdominal spiracular complexes bear only one sensillum (Fig. 2G, 1); caudal segment without lateral spiracular complexes bears posterior spiracular plates; plates bear three, elongate-oval rimae (Fig. $2 \mathrm{H}$,
1), a median scar (Fig. 2H, 2), four interspiracular processes (Fig. $2 \mathrm{H}, 3$ ); caudal sensilla around margin of caudal segement in four-dorsal, sixventral arrangement; sensilla consist of cuticular rings, with smaller papilla centrally each bearing open pores.

In larvae of Neaspilota viridescens Quisenberry, the median oral lobe was reported to be attached basally to the labial lobe (Goeden \& Headrick 1991c); however, we reported that larvae were not observed feeding, and thus we could not ascertain the independent movement of the median oral lobe, as first noted with larvae of Paracantha gentilis, whose median oral lobe is free basally of the labial lobe (Headrick \& Goeden 1990). Our observations of A. thoracica larvae lead us to conclude that the median oral lobe is independently movable whether it is attached basally to the labial lobe or not. The entire structure consisting of the median oral lobe and the labial sclerite moves up and down. This action raises and lowers the median oral lobe and the floor of the mouth lumen independently of the mouth hooks. Based on this action, we believe that the esophagus is compressed, thus creating a suction for intake of plant fluids liberated by the mouth hooks. The median oral lobe functions to extract plant fluids further and to keep plant fibers out of the lumen, as the larvae feed mainly on sap as first reported by Headrick \& Goeden (1990).

Several other characters besides the mouthparts may be useful taxonomically and deserve discussion. Aciurina thoracica larvae bear irregular patches of acanthae. This is in contrast to the rows of acanthae that circumscribe the entire body of other tephritid species (Belcari 1987; Carroll \& Wharton 1989; Headrick and Goeden 1990, 1991; Goeden \& Headrick 1990, 1991a, b,c). The lateral spiracular complexes of tephritid larvae may also have useful taxonomic characters, as the number of sensilla seem to be species specific. The lateral spiracular complexes of $A$. thoracica and other species reported by us, i.e., Stenopa affinis Quisenberry (Goeden \& Headrick 1990), Trupanea californica Malloch (Headrick \& Goeden 1991), T. baccharis (Goeden \& Headrick 1991a), N. viridescens (Goeden \& Headrick 1991c), and Tomoplagia cressoni Aczél (Goeden \& Headrick 1991b) also do not seem to be simply vestigial parts of an amphipneustic tracheal system but, rather, parts of a functional holopneustic system, as each lateral tracheae is lined with taenidia, which can be seen on the inner walls of puparia as part of cast exuviae. Larval spiracular systems are important in determining the phylogeny of the dipteran suborders (McAlpine 1989); these spiracular complexes should be further investigated in this and related families.

Second Instar. Second instar white, subspheroidal, thickest in middle, rounded at ends (Fig. 

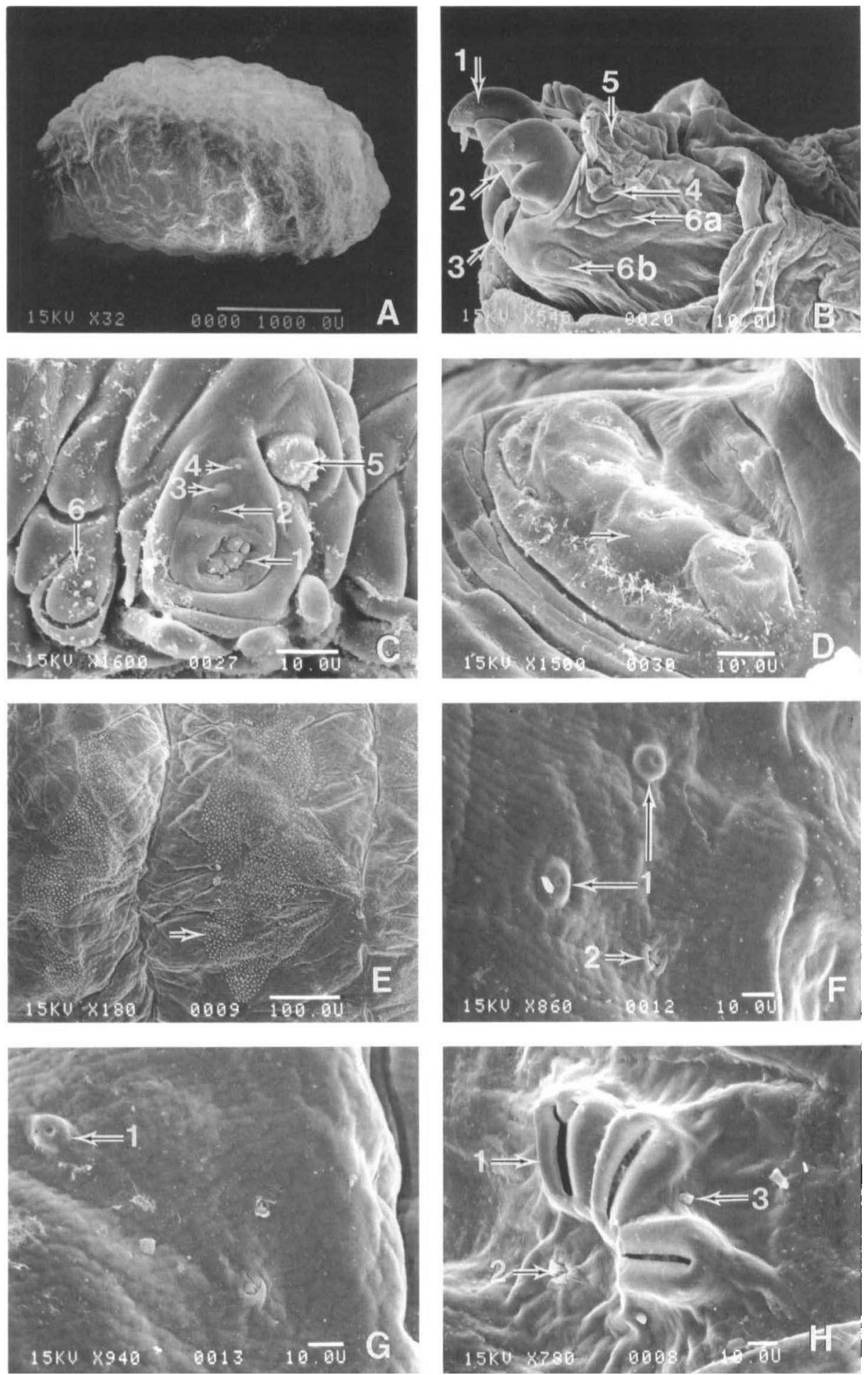

Fig. 2. Third instar of A. thoracica: (A) habitus, anterior to the left; (B) gnathocephalon: (1) mouth hook, (2) median oral lobe, (3) labial lobe sensilla, (4) rugose pads, (5) anterior sensory lobe, (6a) lateral sensillum, (6b) ventrolateral sensillum; (C) right, anterior sense organs (dorsal at top): (1) terminal sensory organ, (2) pit sensory organ, (3) lateral sensory organ, (4) unnamed sensillum, (5) dorsal sensory organ, (6) stomal sense organ; (D) anterior prothoracic spiracle, arrow denotes a single papilla; (E) lateral aspect of abdominal segment III, arrow denotes patch of acanthae; (F) mesothoracic lateral spiracular complex: (1) sensilla, (2) spiracle; (G) metathoracic lateral spiracular complex, (1) sensillum; (H) posterior spiracular plate (dorsal to left), (1) rima, (2) median ecdysial scar, (3) interspiracular process. 

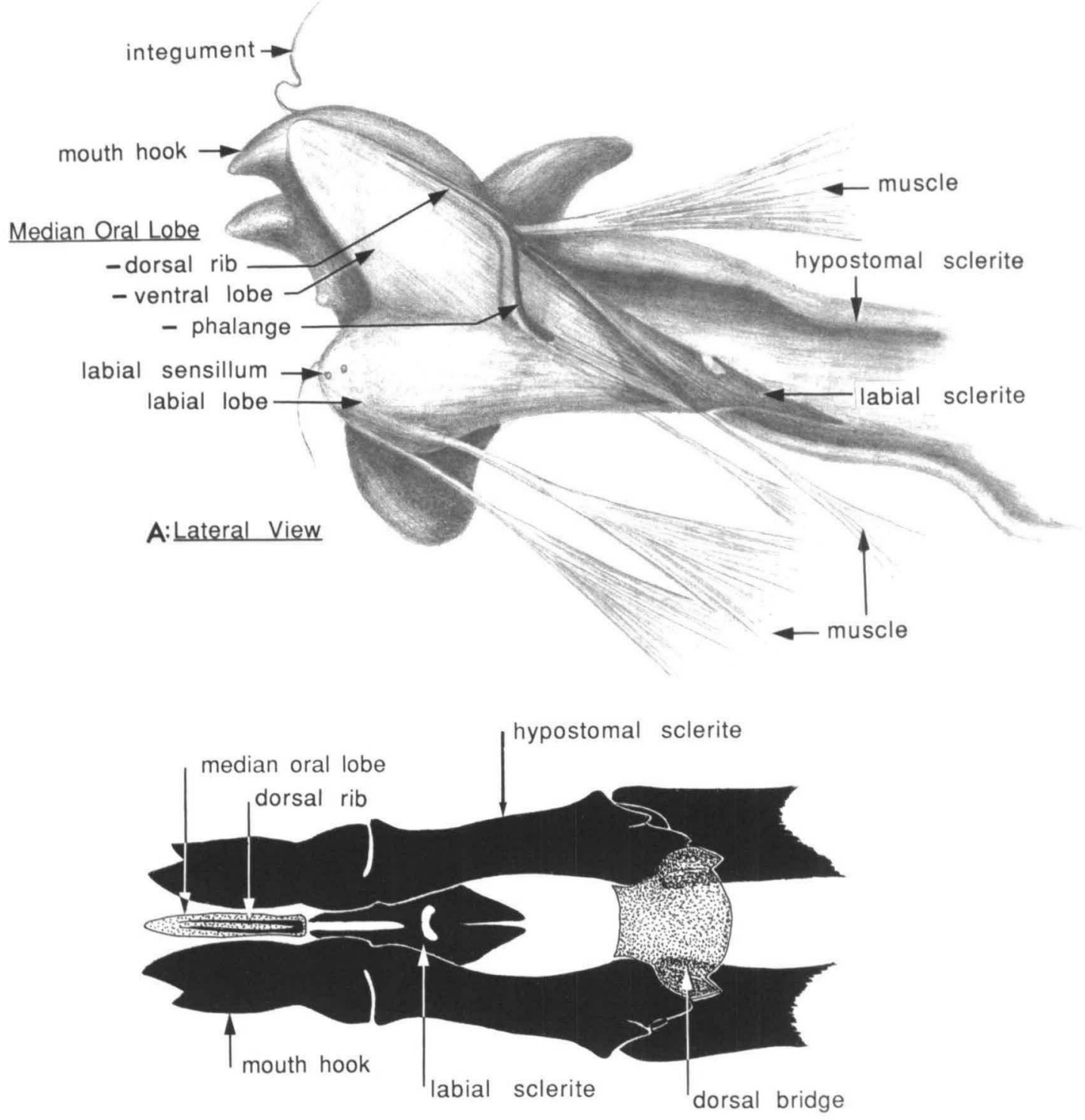

\section{B:Dorsal View}

Fig. 3. (A) Lateral view of dissected mouthparts of A. thoracica, anterior to left, left mouth hook and hypostomal sclerite removed. (B) Dorsal view of anterior portion of cephalopharyngeal skeleton of $A$. thoracica.

4A); gnathocephalon smooth, with four to five rugose pads laterally (Fig. $4 \mathrm{~B}, 1$ ); anterior sensory lobe bears four sensilla; dorsal sensory organ similar in shape, and placement to third instar (Fig. 4C, arrows); mouth hooks with two to three accessory teeth; median oral lobe projects between mouth hooks, ventral lobe basally attached to labial lobe (Fig. 4D, 1), labial lobe bears sensilla on anterior margin (Fig. 2B, 2); gnathocephalon with single verruciform sensilla with single pore on lateral and ventrolateral lobes (Fig. 4D, 3); stomal sense organs lie adjacent to anterior sensory lobe (Fig. 4B, 2); prothorax smooth, bears anterior spiracles on posterior margin (Fig. 4E); body segments with irregular patches of acanthae, no lateral spiracular complexes were observed; caudal segment bears posterior spiracular plates, each with three oval rimae; one of three specimens examined had only two rimae on one plate (Fig. $4 \mathrm{~F}, 1$ ); interspiracular processes reduced to nearly indistinguishable knobs (Fig. 4F, 2).

Puparium. Puparium smooth, black; four averaged $4.01 \pm 0.13 \mathrm{~mm}$ long (range, 3.06-4.35 $\mathrm{mm}$ ), $1.97 \pm 0.06 \mathrm{~mm}$ wide (range, 1.69-2.25 $\mathrm{mm}$ ) (Fig. 5A); anterior end invaginated nearly to posterior margin of prothorax, anterior spiracles protrude dorsolaterally; posterior spiracles open 

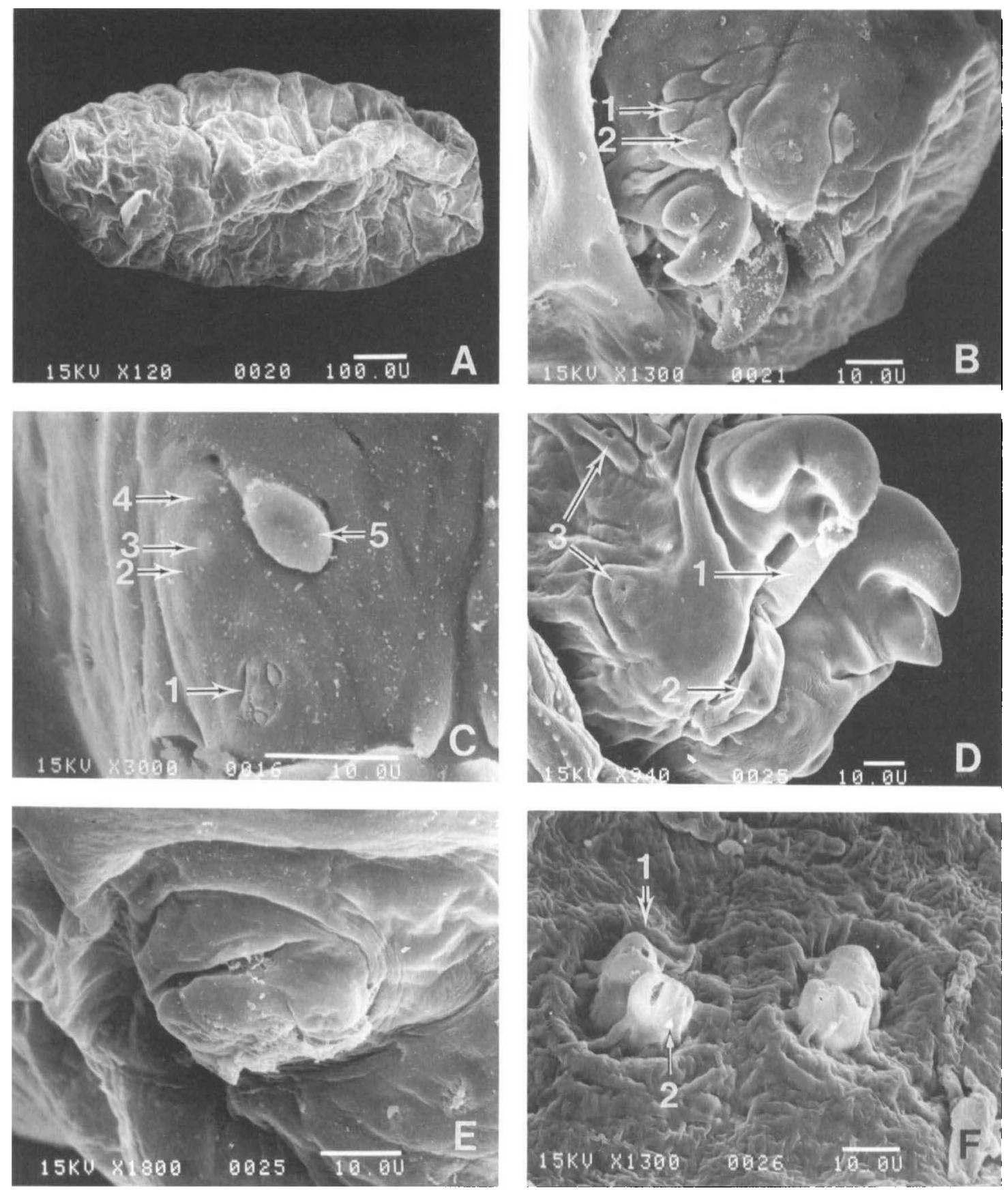

Fig. 4. Second instar of A. thoracica: (A) habitus, anterior to left, ventral side up; (B) gnathocephalon: (1) rugose pads, (2) stomal sense organ; (C) right anterior sense organs (dorsal at top): (1) terminal sensory organ, (2) pit sensory organ, (3) lateral sensory organ, (4) unnamed sensillum, (5) dorsal sensory organ; (D) ventral view of gnathocephalon: (1) median oral lobe, (2) sensilla of the labial lobe, (3) lateral and ventrolateral sensilla; (E) anterior prothoracic spiracle; (F) posterior spiracular plates: (1) denotes only two rimae, (2) small interspiracular process.

and interspiracular processes reduced (Fig. 5B, arrow).

Distribution and Host Range. Aciurina thoracica is known only from California (Foote \& Blanc 1963). Aciurina mexicana occurs in southern Ar- izona, southern California, and northern Mexico where it, too, forms "stem galls" on B. sarothroides (Steyskal 1984). One male that keyed to $A$. mexicana (the only specimen in the collection of R.D.G.) and three males and one female of $A$. 

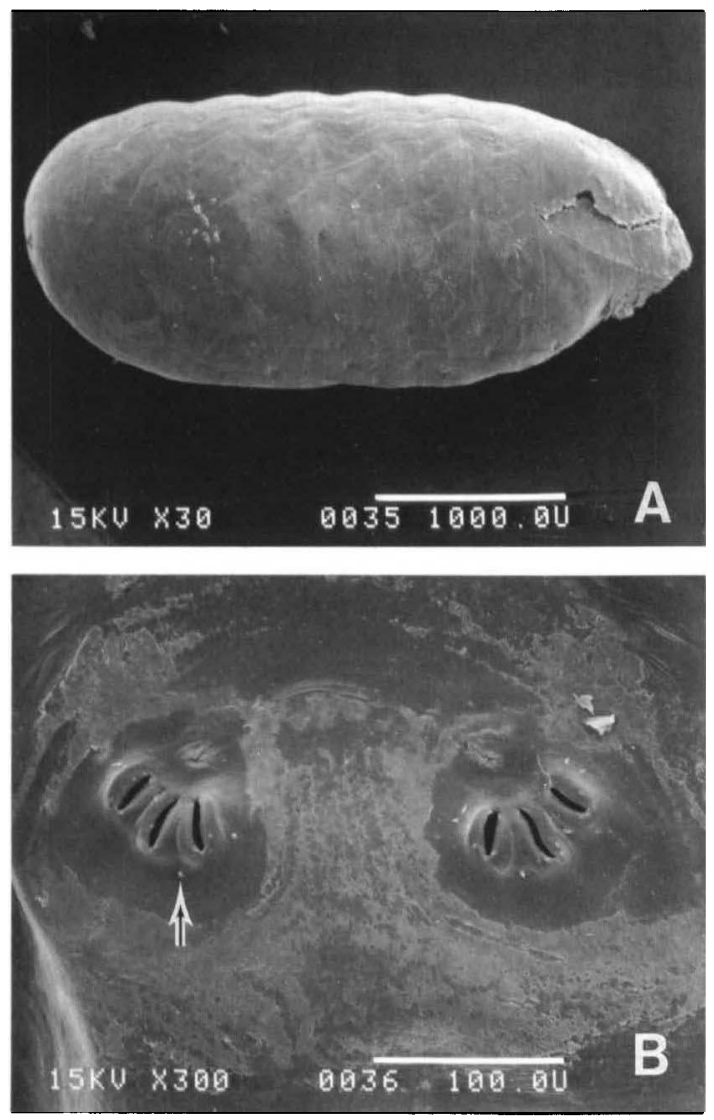

Fig. 5. Puparium of $A$. thoracica: (A) habitus, anterior to the right; (B) posterior spiracular plate (arrow).

thoracica were reared from 56 galls collected at Chariot Canyon on 8 March 1989. This suggests that either these two tephritids are imperfectly separated by characters in the key of Steyskal (1984), or they are sympatric on $B$. sarothroides on the eastern slopes of the Peninsular Mountain Range of southern California. Baccharis sarothroides has a very limited distribution in southern California, but it is widespread in Arizona (Benson \& Darrow 1981). The principal host of A. thoracica apparently is Baccharis pilularis deCandolle, a common species widely distributed along the California coast (Tilden 1951, Foote \& Blanc 1963). Wasbauer (1972) also recorded Baccharis emoryi Gray as a host. These host records indicate that $A$. thoracica is nearly monophagous on these species of Baccharis.

Biology. Egg. Eggs are laid singly near a distal axillary or terminal bud (Fig. 6A) on elongating, succulent, peripheral branches in crowns of male or female host plants. Eggs project partially from ovipositional punctures (Fig. 6A), and the punctures become surrounded by a thin layer of necrotic tissue. The embryo reverses its orientation $180^{\circ}$ just before eclosion, as reported for other gallicolous (Goeden 1990a, Goeden \& Headrick 1991a) and flower-head feeding tephritids (Goeden 1987, Headrick \& Goeden 1991). This behavior allows direct entry into the host tissue by the eclosing first instar.

Larva. The newly eclosed larva tunnels basipetally only a few millimeters into the branch to initiate gall formation. Gall growth and ungalled branch elongation proceed concurrently during the spring. During the second stadium, the gall already reaches its full size (Fig. 6B). The apical bud may resume growth and one or more lateral buds on the gall may initiate growth (Fig. 6C). Meanwhile, the larva within the gall continues to enlarge the single central chamber as it molts and grows (Fig. 6D). However, the larva primarily feeds on sap expressed from the expanded pith parenchyma, which it scores with its mouth hooks (see above). Little frass or feces are found inside the galls, and none is ejected through holes in the gall wall as occurs with some gallicolous Lepidoptera (Goeden \& Ricker 1981).

The gall of $A$. thoracica is clavoidal (Fig. $6 \mathrm{E}$ ) or ellipsoidal (Fig. 6C), depending respectively on whether or not the apical bud is killed by larval feeding, as discussed for other gall formers by Goeden \& Ricker (1981) and Goeden (1988, 1990a). Often, the expanded base of an axillary branch arises like a webbed thumb on one side of a gall, giving it an asymmetrical, "mitten-like" shape (Fig. $6 \mathrm{C}$ and F). The galls are smooth and yellow-green when young but are streaked with red, darken further to brown, and become roughened and corky with age.

Eighty-four full-size, overwintering galls collected at Otay Mesa on 15 February 1990 averaged $10.0 \pm 0.2 \mathrm{~mm}$ in length (range, $5-16 \mathrm{~mm}$ ) and $4.4 \pm 0.1 \mathrm{~mm}$ in width (range, $2.5-7 \mathrm{~mm}$ ). Twenty-four overwintering galls collected at $\mathrm{Al}$ pine on 12 January 1989 averaged $12.6 \pm 0.4 \mathrm{~mm}$ long (range, $10-17 \mathrm{~mm}$ ) and $3.9 \pm 0.2 \mathrm{~mm}$ wide (range, 2-5.5 mm). And 56 galls collected from Chariot Canyon on 8 March 1989 were $9.2 \pm 0.3$ $\mathrm{mm}$ long (range, 5-17 mm). These last galls apparently had been initiated later in the season, as $51(91 \%)$ bore terminal and side branches topped with dried flower heads (Fig. 6G). Galls initiated earlier in the preceding year at the other two sites only bore vegetative branches, also indicative of the number of nodes incorporated in a gall. Nodes per gall averaged $2.5 \pm 0.1$ (range, 1-5) at Otay Mesa and $2.4 \pm 0.2$ (range, 1-4) at Alpine.

Puparium. The single locules within nine mature galls bearing intact puparia measured $6.6 \pm$ $0.4 \mathrm{~mm}$ in length (range, $5.3-9 \mathrm{~mm}$ ) and $2.4 \pm 0.1$ $\mathrm{mm}$ in width (range, $2.1-3 \mathrm{~mm}$ ), which was only slightly larger than the puparia described above (Fig. 6F). Just before pupariation, the third instar cuts a round exit hole, $\approx 2 \mathrm{~mm}$ across, laterally in the gall wall. The epidermal window that covers this exit hole is broken by the adult as it emerges 

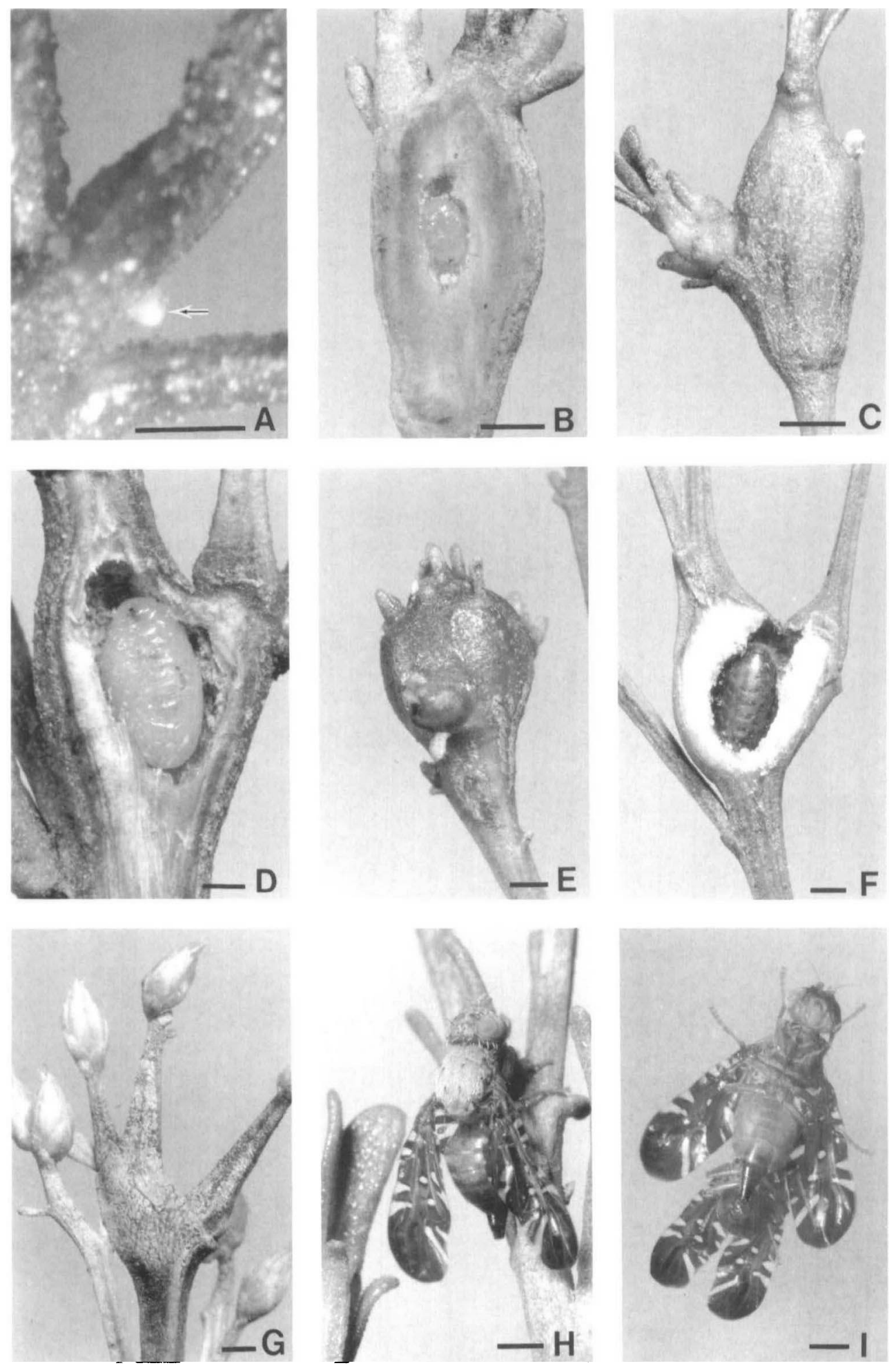

Fig. 6. Life stages and galls of A. thoracica on Baccharis sarothroides: (bar, $1 \mathrm{~mm}$ ) (A) egg protruding from ovipositional site (arrow); (B) sagittal section of immature gall containing first instar larva; (C) lateral view of immature gall; (D) third instar larva feeding head-up in a mature gall; (E) terminal mature gall; (F) sagittal section of mature gall containing a puparium; (G) mature gall with branch and flower-head formation; (H) female; (I) mating pair, ventral view. 
from the puparium, which always is oriented with its anterior end near the window.

Adult. Adults are long lived; five females lived an average of $63 \pm 6 \mathrm{~d}$ (range, 45-76 d); and, three males lived $86 \pm 8 \mathrm{~d}$ (range, 70-95 d). Females (Fig. $6 \mathrm{H}$ ) are synovigenic, and apparently like Eutreta diana (Osten Sacken) (Goeden 1990a) bear numerous immature ova and substantial fat body tissue at emergence, which is immediately converted into their initial egg compliment. Two 2-mo-old females that had not oviposited since their emergence contained totals of 95 and 62 ova, all of which showed ovisorption, as described by Goeden (1990b) for Eutreta simplex Thomas. One field-collected female contained totals of 14 full-size ova and numerous uncounted immature ova; two other swept females contained 68 and 123 full-sized ova. The first female may already have oviposited when collected.

Mating Behavior. In 13 trials, male and female adults were paired for $\approx 1 \mathrm{~h}$. In each trial, the behavior of adults was observed and recorded using a tally system, i.e., predetermined behavioral activities during each encounter between paired adults were checked off, and the duration of each encounter was measured. The behavior categories were based on descriptions of adult behavior of $A$. mexicana reported by Jenkins (1990). Six additional trials were run for $\approx 1.5 \mathrm{~d}$. This increased length in exposure time allowed the acclimation of adults to each other and facilitated expression of copulatory behavior. Unlike the mating trials with A. mexicana described by Jenkins (1990), pairs of A. thoracica required at least a day together before mating took place. During each of the initial $13 \mathrm{l}-\mathrm{h}$ trials, only routine individual behaviors, e.g., resting, feeding, grooming, excretion, and male courtship behaviors, were expressed.

The 1-h trials were tallied according to which sex approached the other first or by simultaneous approaches. Males approached females an average of 3.3 times (range, $1-6 ; n=39$ ), females approached males an average of 2.0 times (range, $1-4 ; n=24)$, and simultaneous approaches averaged 1.4 times (range, $1-4 ; n=17$ ) for a total average of 6.7 approaches during a 1 -h observation period. Overall, 80 encounters averaged 3.6 min over 13 trials (range, 2.3-6.2 min). Once an approach was observed, the actions and reactions of each adult were marked. The following are descriptions of observed behaviors during these encounters.

Wing Displays. Both sexes displayed asynchronous wing supination or the "slow signal" described for A. mexicana by Jenkins (1990). This display was also described for T. californica (Headrick \& Goeden 1991). It consists of extending one wing forward at a time to $\approx 90^{\circ}$ and supinating the wing blade to $90^{\circ}$ during the extension. An embellishment of this display com- monly observed is a slight, intermittent rotation of the wing blade, i.e., rhythmic, intermittent pronation while overall supinating the blade. The other wing at rest over the dorsum also rotates slightly in phase with the extending wing. Jenkins (1990) described this as "intermittent jerks accompanied by slight rotational adjustments" for A. mexicana. Asynchronous supination is common to most, but not all 16 genera of Tephritidae examined by us to date (unpublished data). Asynchronous wing supinations have been reported for four species of Aciurina to date (Tauber \& Tauber 1967, Dodson 1987, Jenkins 1990, and the present study). During the 1-h trials, adults displayed asynchronous supination equally between the sexes in $38(48 \%)$ of 80 encounters. This display was not necessarily performed at or between members of a pair, and as noted by Jenkins (1990), it could not be associated with any particular activity. Jenkins (1990) differentiated between a "slow signal" and "wing waving" in A. mexicana; the latter movement was defined exactly the same as the slow signal, but it is done more rapidly. We could not substantiate this difference with A. thoracica, in which "wing waving" and "slow signals" apparently are extremes of a continuum within the movement we term asynchronous supination.

Both sexes also displayed synchronous supination, in which both wings were extended forward from a resting position over the dorsum to $90^{\circ}$, i.e., perpendicular to the long axis of the body, while concurrently the wing blade was supinated to $90^{\circ}$, i.e., perpendicular to the substrate. No rotational movements were observed in this display, as with asynchronous supination. Although both sexes were observed displaying synchronous supination, males and females used this display differently. During courtship, males held their wings extended at $\approx 45^{\circ}$ from their bodies and supinated to $45-90^{\circ}$ while facing a female. The wings were then synchronously extended forward to $\approx 90^{\circ}$, then relaxed back to $45^{\circ}$ $\approx 1 / \mathrm{s}$. This display was used by males when approaching females during courtship. Jenkins (1990) described this movement as "wing flicking" for A. mexicana. Females used synchronous supination for aggressive displays; the wings were extended to $90^{\circ}$, either from the resting position over the dorsum or from $45^{\circ}$. Generally during synchronous supination, the wings of both the male and female were less relaxed as their state of excitment intensified, i.e., the wings remained partially extended throughout the display episode when the adults were more excited. Jenkins (1990) separated synchronous supination into "wing fanning," "wing flicking," and "wing thrusting" for A. mexicana. Again, for A. thoracica, we could not make these distinctions, which appeared to be extremes of a continuum of a basic wing movement common to 
most of the 54 species of Tephritidae studied by us to date (unpublished data).

Courtship. Male courtship displays consisted of three elements: (1) synchronous wing supination, (2) abdominal pleural distension, and (3) rocking the body from side to side. These also were traits common to male courtship displays of A. mexicana (Jenkins 1990). However, A. thoracica never was observed to display nuptial gift presentation as reported for A. mexicana (Jenkins 1990). The three elements of male courtship display in A. thoracica were observed in 10 of 13 1-h trials. Jenkins (1990) reported that males displayed for an average $8.7 \mathrm{~min}$, but $A$. thoracica males displayed for an average of $3.4 \mathrm{~min}$ (range, $1-19 \mathrm{~min} ; n=50$ ). However, females were either unresponsive or displayed aggression toward courting males using wing thrusts and lunges in our trials. Male courtship in A. thoracica culminates when the male nears the female and tries to move behind her.

Copulation. Copulation behavior was observed only when adults of $A$. thoracica remained together for more than a day. Courting males became more aggressive as courtship continued. Once behind a female, a male chased her while trying to grasp her wings or hindlegs with his front legs, a tactic common to all Aciurina species studied to date (Tauber \& Tauber 1967, Dodson 1987, Jenkins 1990; unpublished data). If the male successfully grasped the female, he hung on until she stopped moving and then mounted her and began copulatory induction behavior. This behavior consisted of the male rubbing the ventral side of the upturned oviscape with his hind tarsi. In this position, the male front legs grasped the base of the abdomen, the middle legs grasped the base of the oviscape, and the hind legs were pressed against the ventral aspect of the oviscape. Copulation began when the female exerted her aculeus into the male epandrium. In one trial, a male was observed to mount a female, remain on her dorsum for $2 \mathrm{~min}$, dismount, and immediately remount, then remain for another $8 \mathrm{~min}$, until he dismounted again. This male was not able to engage the female aculeus, and thus no mating took place. The final position of the male in relation to the female was similar to the initial mounting position, except that he was positioned farther back on the female with his head above the middle of her abdomen and with his hindlegs resting on the substrate (Fig. 6I). As Jenkins (1990) noted for A. mexicana, the male abdomen returned to a normal size once copulation was initiated. Two observed copulations lasted 67 and 72 min, compared with the 1.5 -h average copulation time for A. mexicana (Jenkins 1990).

Seasonal History. Aciurina thoracica generally is univoltine on B. sarothroides in southern California, although a second annual generation may occur facultatively, as reported with other gall-forming tephritids, e.g., Procecidochares spp. (Silverman \& Goeden 1980; R.D.G., D.H.H. \& J. A. Teerink, unpublished data) and T. baccharis (Goeden \& Headrick 1991a). On six regularly irrigated and fertilized potted seedlings in a greenhouse, $40 \mathrm{~A}$. thoracica continuously developed from eggs to adults in $2.5-3$ mo during May-July 1989. Therefore, should late seasonal rains extend spring plant growth, or late-summer to early-fall rainfall stimulate a second flush of growth, it is conceivable that a partial second generation might be produced. The occurrence of flowering in the fall (June-October; Munz 1974; personal observations) and our finding of galls on floral branches of $B$. sarothroides (Fig. 6G) may support this hypothesis, although no direct evidence of two generations was found at our three main study sites.

Adults emerge in January through March from galls on B. sarothroides, live, and probably oviposit through most of April in southern California. Gall and larval development generally proceed as described above for the remainder of the year, until pupariation and adult emergence are triggered by renewed host-plant growth triggered by winter rainfall. Fly emergence and seasonal history of $A$. thoracica on $B$. pilularis apparently are delayed, as Foote \& Blanc (1963) reported flies swept from this host in northern coastal California in June-October and emergence from galls in mid-March. R.D.G. also has swept $A$. thoracica from $B$. pilularis in mid-April along the central and southern California coast (Goeden 1986; unpublished data). These earlyand late-season sweep records also suggest the occurrence of two annual generations on this alternate host.

Natural Enemies. Five species of chalcidoid Hymenoptera adults were reared from $A$. thoracica during this study. One specimen of Dinarmus sp. (Pteromalidae) was recovered from a puparium as a solitary, primary endoparasitoid. Eleven Eupelmus sp. (Eupelmidae) were reared as solitary, primary parasitoids; two as pupal (larval-pupal?) endoparasitoids, and the rest as larval ectoparasitoids. Seven Eurytoma sp. (Eurytomidae) were solitary, primary, larval ectoparasitoids. Two Pteromalus sp. and two Mesopolobus sp. (Pteromalidae) were solitary, primary, larval ectoparasitoids.

Thirteen (35\%) of 37 galls sampled at Alpine on 13 January 1989 contained parasitoids; as did $30(41 \%)$ of 73 galls collected at San Ysidro on 15 February 1989 and 59 (86\%) of 69 galls sampled in Chariot Canyon on 10 March 1989. One gall in the last sample appeared to have been opened apically by a bird and the puparium within destroyed, which was the only sign of this type of predation on $A$. thoracica, reported for other gallicolous tephritids by Goeden (1990a) and Goeden \& Headrick (1991a). 


\section{Acknowledgments}

We sincerely thank D. W. Ricker, now retired, and J. A. Teerink for technical assistance, including the photographs in Fig. 9. We also thank F. L. Blanc, G. Gordh, J. Pinto, and J. A. Teerink for their helpful comments on early drafts of this manuscript; and J. Luhman, who identified the parasitoids when he was with the Department of Entomology, University of California, Riverside.

\section{References Cited}

Belcari, A. 1987. Contributi alla conoscenza dei ditteri Tefritidi. IV. Descrizione della larva di terza eta' di Acanthiophilus helianthi (Rossi), Dacus oleae (Gmel.), Ceratitis capitata (Wied.), Acida cognata Wied. e considerazioni preliminari sule differenziazioni morfologiche legate al diverso trofismo. Frustula Entomol. 10: 83-125.

Benson, L. \& R. A. Darrow. 1981. Trees and shrubs of the southwestern deserts, 3rd ed. University of Arizona Press, Tucson.

Boldt, P. 1989. Baccharis (Asteraceae), a review of its taxonomy, phytochemistry, ecology, economic status, natural enemies, and the potential for biological control in the United States. Texas Agric. Exp. Sta. Misc. Publ. 1674: 1-32.

Carroll, L. E. \& R. A. Wharton. 1989. Morphology of the immature stages of Anastrepha ludens (Diptera: Tephritidae). Ann. Entomol. Soc. Am. 82: 201-214.

Cavender, G. L. \& R. D. Goeden. 1984. The life history of Paracantha cultaris (Coquillett) on wild sunflower, Helianthus annuus L. ssp. lenticularis (Douglas) Cockerell, in southern California (Diptera: Tephritidae). Pan-Pac. Entomol. 60: 213218.

Curran, C. H. 1932. New species of Trypaneidae, with a key to the North American genera. Am. Mus. Novit. 556: 1-19.

Dodson, G. 1987. Biological observations on Aciurina trixia and Valentibula dodsoni (Diptera: Tephritidae) in New Mexico. Ann. Entomol. Soc. Am. 80: 494-500.

Dodson, G. \& S. B. George. 1986. Examination of two morphs of gall-forming Aciurina (Diptera: Tephritidae): ecological and genetic evidence for species. Biol. J. Linn. Soc. 29: 63-79.

Foote, R. H. \& F. L. Blanc. 1963. The fruit flies or Tephritidae of California. Bull. Calif. Insect Surv. 7: $1-117$.

Goeden, R. D. 1986. New records of Tephritidae (Diptera) from Santa Cruz Island, California. PanPac. Entomol. 62: 326-328.

1987. Life history of Trupanea conjuncta (Adams) on Trixus californica Kellogg in southern California (Diptera: Tephritidae). Pan-Pac. Entomol. 63: 284291.

1988. Gall formation by the capitulum-infesting fruit fly, Tephritis stigmatica (Diptera: Tephritidae). Proc. Entomol. Soc. Wash. 90: 37-43.

1990a. Life history of Eutreta diana (Osten Sacken) on Artemisia tridentata Nuttall in southern California (Diptera: Tephritidae). Pan-Pac. Entomol. 66: $24-32$.

1990b. Life history of Eutreta simplex Thomas on Artemisia ludoviciana Nuttall in southern California (Diptera: Tephritidae). Pan-Pac. Entomol. 66: 33-38.
Goeden, R. D. \& D. H. Headrick. 1990. Notes on the biology and immature stages of Stenopa affinis Quisenberry (Diptera: Tephritidae). Proc. Entomol. Soc. Wash. 92: 641-648.

1991a. Life history and descriptions of immature stages of Tephritis baccharis (Coquillett) on Baccharis salicifolia (Ruiz \& Pavon) Persoon in southern California (Diptera: Tephritidae). Pan-Pac. Entomol. 67: 86-98.

1991b. Notes on the biology, hosts, and immature stages of Tomoplagia cressoni Aczél in southern California (Diptera: Tephritidae). Proc. Entomol. Soc. Wash. 93: 549-558.

1991c. Life history and descriptions of immature stages of Neaspilota viridescens Quisenberry (Diptera: Tephritidae) on native Asteraceae in southern California. Proc. Entomol. Soc. Wash. 94: 59-77.

Goeden, R. D. \& D. W. Ricker. 1981. Life history of the gall-forming moth, Carollela beevorana Comstock, on the ragweed, Ambrosia dumosa (Gray) Payne, in southern California (Lepidoptera: Cochylidae). Pan-Pac. Entomol. 57: 402-410.

Headrick, D. H. \& R. D. Goeden. 1990. Description of the immature stages of Paracantha gentilis (Diptera: Tephritidae). Ann. Entomol. Soc. Am. 83: 220-229.

1991. Life history of Trupanea californica Malloch (Diptera: Tephritidae) on Gnaphalium spp. in southern California. Proc. Entomol. Soc. Wash. 93: $559-570$.

Jenkins, J. 1990. Mating behavior of Aciurina mexicana (Aczél) (Diptera: Tephritidae). Proc. Entomol. Soc. Wash. 92: 66-75.

Jenkins, J. \& W. J. Turner. 1989. Revision of the Baccharis-infesting (Asteraceae) fruit flies of the genus Tephritis (Diptera: Tephritidae) in North America. Ann. Entomol. Soc. Am. 82: 674-685.

McAlpine, J. F. 1989. Phylogeny and classification of the Muscomorpha, pp. 1397-1502. In J. F. McAlpine et al. [eds.], Manual of Nearctic Diptera, vol. 3. Research Branch, Agriculture Canada Monograph No. 32, Ottawa, Canada.

Munz, P. A. 1974. A flora of southern California. University of California Press, Berkeley.

Silverman, J. \& R. D. Goeden. 1980. Life history of a fruit fly, Procecidochares sp., on the ragweed, Ambrosia dumosa (Gray) Payne, in southern California (Diptera: Tephritidae). Pan-Pac. Entomol. 56: 283-288.

Steyskal, G. C. 1984. A synoptic revision of the genus Aciurina Curran, 1932 (Diptera: Tephritidae). Proc. Entomol. Soc. Wash. 86: 582-598.

Tauber, M. J. \& C. A. Tauber. 1967. Reproductive behavior and biology of the gall-former Aciurina ferruginea (Doane) (Diptera: Tephritidae). Can. J. Zool. 45: 907-913.

Teskey, H. J. 1981. Morphology and terminologylarvae, pp. 65-88. In J. F. McAlpine et al. [eds.], Manual of Nearctic Diptera, vol. 1. Research Branch, Agriculture Canada, Monograph 27, Ottawa, Canada.

Tilden, J. W. 1951. The insect associates of Baccharis pilularis De Candolle. Microentomology. 16: 149-188.

Wangberg, J. K. 1981. Gall-forming habits of Aciu- 
rina species (Diptera: Tephritidae) on rabbitbrush (Compositae: Chrysothamnus spp.) in Idaho. J. Kans. Entomol. Soc. 54: 711-732.

Wasbauer, M. W. 1972. An annotated host catalog of the fruit flies of America north of Mexico (Diptera:
Tephritidae). Calif. Dep. Agric. Bur. Entomol. Occas. Pap. 19: 1-172.

Received for publication 24 February 1992; accepted 21 August 1992. 